\title{
Violência urbana: uma análise dos conceitos de professores do ensino fundamental
}

\author{
Urban violence: an analisys of elementary \\ school teachers concepts
}

Marilena Ristum ${ }^{1}$

Ana Cecília de Sousa Bastos 1

\footnotetext{
1 Departamento de Psicologia, Universidade Federal da Bahia. Rua Rodrigo Argolo 163/302, Rio Vermelho, 41940-220, Salvador BA. ristum@ufba.br
}

\begin{abstract}
The main objective is to describe and contextualize the violence concept of fundamental education teachers. It was also intended to compare the results obtained with teachers of public and particular schools. The data was obtained through semi-structured interviews with 47 teachers of four schools, two of them public and two particular. A category system, extracted by the data, allowed to describe and contextualize the violence concept that, according to the results, can be characterized, mainly, by the classes of delinquency and structural violence; by the modalities of marginal, scholar and familiar violence; and by the forms of physical aggression, robbery and verbal aggression. The differences between teachers of public and particular school were related to characteristics of their work environment.
\end{abstract}

Key words Violence concept, Teachers, Public and particular schools
Resumo O objetivo principal foi descrever e contextualizar o conceito de violência de professoras do ensino fundamental. Pretendeu-se, também, comparar os resultados obtidos com professoras de escolas públicas com os de escolas particulares. Os dados foram obtidos através de entrevista semi-estruturada, com 47 professoras de quatro escolas, duas públicas e duas particulares. Um Sistema de Categorias, extraído dos dados, permitiu descrever e contextualizar o conceito de violência que, de acordo com os resultados, se caracteriza, preponderantemente, pelas classes violência de delinqüência e estrutural; pelas modalidades violência de marginais, escolar e familiar; pelas formas agressão física, assalto e agressão verbal. As diferenças entre professoras de escolas públicas e particulares foram relacionadas a características de seus ambientes de trabalho.

Palavras-chave Conceito de violência, Professoras, Escolas públicas e particulares 


\section{Introdução}

O interesse pelas questões educacionais e escolares e o interesse pelo estudo da violência que ocorre em larga escala nas sociedades, especialmente nas grandes cidades, surgido da participação em um trabalho em comunidade de baixa renda que apontou, como problema principal, a violência, nas suas múltiplas formas ( $\mathrm{No}-$ ronha et al., 1997), conduziram ao estudo do conceito de violência de professores.

As formulações da teoria sociohistórica, proposta inicialmente por Vygotsky, forneceram as bases necessárias às justificativas para os propósitos deste trabalho, colocando a violência e a interação professor-aluno como fenômenos sociais relevantes para a construção da individualidade dos alunos, especialmente em um período de desenvolvimento em que a internalização de valores sociais, morais, éticos e religiosos ocorre com maior intensidade. Afirma-se, assim, a importância da participação mediacional dos professores, em sua prática sociopedagógica em sala de aula, no desenvolvimento dos processos mentais dos alunos, incluindo construção, ampliação e mudança conceitual.

Sendo os conceitos socialmente construídos (Vygotsky, 1984), a formação do conceito dos alunos do ensino fundamental acerca da violência teria a participação das concepções dos professores com os quais mantêm um tipo de relação relevante.

Com este mesmo enfoque, Silva e Tunes (1999) realizaram um trabalho em que foram analisadas as concepções de professores a respeito do processo ensino-aprendizagem, através de seus relatos verbais. As concepções eram entendidas, pelas autoras, como compreensão, formação de idéias, noções. Os resultados produzidos por este estudo permitiram afirmar que ...o discurso do professor é uma ação do mesmo e não se dissocia de sua ação em sala de aula. $O$ sujeito falante e o sujeito agente são o mesmo. As pessoas não deixam de ser o que são quando falam de si. É possivel estudar o pensamento das pessoas por meio de seus relatos verbais, e, nas condiçôes reais de vida, esse pensamento não se separa, dicotomicamente, de suas ações (Silva e Tunes, 1999).

Ao enfatizar os relatos verbais, o falar de si e de suas vidas, como dados importantes para a psicologia, essas autoras evidenciam uma posição concordante com a de Bruner, segundo a qual as palavras que compõem a fala são cons- tituídas de significado e sentido, e isto as coloca em relevo no estudo psicológico do homem.

$O$ presente trabalho pretendeu responder à indagação sobre como se estruturam as concepções de violência de professores do ensino fundamental, de forma a abarcar as relações sociais envolvidas nessas concepções. Na mesma direção das posições de Bruner (1997) e de Silva e Tunes (1999), julgou-se que as falas dos professores poderiam fornecer importantes informações acerca do seu pensamento, dando acesso à sua consciência acerca da violência.

\section{Compreendendo a violência}

Um fenômeno do porte da violência é de tal complexidade que seria muito difícil abarcá-lo como um todo. Assim, tornou-se necessário fazer um recorte, direcionado pelo objetivo da pesquisa, de forma a possibilitar um melhor sentido metodológico e uma maior compreensão dos dados que seriam obtidos. Foram quatro os aspectos selecionados que denotam a complexidade da violência:

\section{1) A polissemia do conceito e os problemas da definição de violência}

A violência é conceituada, na literatura, de muitas formas diferentes; as rotulações e classificações são apresentadas sem a especificação de critérios, ou com critérios confusos, de forma a dificultar seu uso por outros pesquisadores. Conseqüentemente, são muitas as dificuldades encontradas na complementação ou na comparação entre os dados de diferentes pesquisas.

A questão subjacente ao problema da definição, segundo Emery e Laumann-Billings (1998), reside no fato de a conceituação de violência ser inerentemente dirigida pelo julgamento social, cuja pluralidade quase impede uma formulação consensual. Além disso, muitas definições são direcionadas pelos objetivos dos trabalhos e da aplicabilidade de seus resultados, o que amplia o leque de variações. Esta questão remete diretamente ao segundo aspecto focalizado.

\section{2) A controvérsia na delimitação do objeto da violência}

Ao lado das dificuldades relativas à definição da violência, tem-se o problema da delimi- 
tação de seu objeto. Aqui, além das muitas formas que a violência pode assumir, coloca-se, ainda, o problema da intensidade da violência, estando, na regência da referida delimitação, as normas legais e culturais que orientam a classificação das ações humanas em violentas e nãoviolentas.

Um importante ponto dessa controvérsia se localiza na redução da violência à delinqüência, produto de origens históricas de identificação da violência com a criminalidade, muito presente no senso comum. Credita-se à mídia uma atuação capaz de contribuir grandemente para a manutenção desta identificação, tão criticada por Minayo (1994), por deixar de incluir a dominação política e econômica nas sociedades e todas as implicações dela decorrentes, desconsiderando, portanto, as violências estrutural e de resistência. Acrescente-se que essa visão reducionista e preconceituosa, de acordo com Cruz Neto e Moreira (1999), aponta para a segurança pública e a repressão policial como as únicas esferas em que se dariam o combate e a prevenção da violência. Isto remete à questão da causalidade da violência.

\section{3) A quantidade, variedade e interação de suas causas}

A literatura apresenta um quadro em que as discordâncias quanto às causas se referem a sua identificação, a sua classificação e rotulação, à atribuição de sua importância e, enfim, à própria concepção de causalidade da violência. Em vista desse quadro, numa tentativa de sistematizar a grande diversidade e quantidade de causas apontadas pelos trabalhos consultados, procurou-se classificá-las em função de como o ambiente em que elas se encontram estão relacionados aos que praticam a violência, em um modelo que guarda muitas semelhanças com a proposta de Bronfenbrenner (1996), para o estudo do desenvolvimento humano. Assim, foram estabelecidas duas grandes categorias: causas contextuais e causas pessoais, sendo que as contextuais foram divididas em duas subcategorias, de acordo com sua maior ou menor proximidade em relação aos agressores: causas contextuais distais e contextuais proximais. As contextuais distais são produzidas pelas conjunturas econômica, social, política e cultural. Nesta categoria, a literatura relata, por exemplo, pobreza, exclusão social, desemprego, fome, discriminação social, impunidade, autoritarismo, violação de direitos humanos, etc.
Sua presença é marcante no sentido de que moldam todo um modo de ser e de funcionar de uma sociedade. As contextuais proximais se referem a eventos relacionados à violência que estão presentes no ambiente e com os quais os indivíduos que praticam a violência têm contato direto. A literatura aponta, por exemplo, modelos de violência em casa, na rua ou na TV, desorganização familiar, uso freqüente de punição em diversas instituições sociais etc. As causas pessoais, tanto biológicas como psicológicas, são referidas como no caso de consumo de drogas e álcool, desequilíbrio emocional, questões passionais, temperamento, índole, etc.

No cenário de diversidade e discordâncias quanto às causas da violência foi possível, entretanto, identificar, na literatura, uma clara uniformidade em relação a alguns aspectos que podem ser sintetizados em: a) multicausalidade da violência; b) interação entre os fatores causais e c) atuação conjunta de fatores contextuais e pessoais na constituição da violência.

Um outro enfoque na abordagem das origens da violência remete a uma pergunta antiga, mas recorrente: a violência faz parte da natureza do homem?

\section{4) A falta de consenso sobre a natureza da violência}

Encontram-se aqui duas posições extremadas e opostas. Uma delas focaliza sua natureza inata, como a posição de importantes etólogos que afirmam a existência de um instinto geral de agressão (Lorenz, 1979; Eibl-Eibsfeldt, 1970). Coloca-se também a posição de psicanalistas como Costa (1986), que, com base nas formulações de Freud, afirma a existência de instinto agressivo no homem e distingue agressividade de violência; e a de Figueiredo (1998), que afirma a impossibilidade de uma vida social destituída de agressividade e violência, acrescentando que a violência é estruturante e constitutiva da subjetividade humana. Dadoun (1998), num enfoque filosófico da posição freudiana, apresenta o homo violens como definido e estruturado fundamentalmente pela violência.

A outra posição advoga que a violência tem suas raízes na aprendizagem, a exemplo da posição de Bandura (1973), que propõe, na perspectiva da teoria da aprendizagem social, que o comportamento agressivo é adquirido por modelação (aprendizagem por observação de modelos) ou por experiência direta e sob influên- 
cia de fatores biológicos estruturais. Para Skinner (1976; 1982), o comportamento violento do homem é modelado na sua história ontogenética e mantido pelas conseqüências reforçadoras que produz.

Os estudos em sociologia, antropologia, política, história e psicologia social têm focalizado a violência como um fenômeno gerado nos processos sociais, históricos e culturais, afirmando a inadequação de se estudar a violência de forma independente da sociedade que é responsável pela sua produção (Minayo, 1994, 1997; Souza, 1993; Martucelli, 1999; Gullo, 1998).

O presente trabalho assume, coerentemente com os pressupostos da psicologia sociohistórica, que a violência, como parte das ações humanas, é um fenômeno socialmente construído e que, portanto, qualquer estratégia que pretenda combatê-la deve trilhar o caminho da construção de uma nova história.

\section{Metodologia}

\section{Objetivos da pesquisa}

O objetivo principal foi descrever e contextualizar o conceito de violência de professoras do ensino fundamental. Pretendeu-se, também, uma comparação entre os resultados obtidos com professoras de escolas públicas e os de escolas particulares.

\section{A entrada em campo e os procedimentos}

A seleção das escolas - foram selecionadas quatro escolas de primeiro grau, duas públicas e duas particulares, de porte médio, com base em cinco critérios, sendo os dois primeiros direcionados pelos objetivos da pesquisa: (1) divididas entre públicas e particulares; e (2) ter o primeiro segmento do ensino fundamental. Os dois critérios seguintes procuravam garantir que algumas variáveis fossem semelhantes nas quatro escolas, de modo a viabilizar a comparação entre elas; (3) localizadas em um mesmo bairro; e (4) assemelhar-se quanto ao porte, em termos do número de alunos e professores. $\mathrm{O}$ quinto critério referia-se à concordância da escola em participar do trabalho.

A reunião nas escolas - em cada escola, realizou-se uma reunião com todas as professoras (eram todas do sexo feminino), com a presen- ça, também, da direção e da coordenação pedagógica. Nessa reunião, foram expostos os objetivos, os procedimentos e a relevância do trabalho. Ao final, solicitou-se a anuência das professoras à participação no trabalho.

A entrevista inicial - como a anuência foi total, todas as professoras do primeiro segmento do primeiro grau, em número de 47 , foram submetidas a uma entrevista inicial, para a coleta de dados pessoais e profissionais e para uma maior aproximação entre pesquisadora e entrevistada.

As professoras -47 professoras participaram do trabalho. Sua idade média era de 40 anos e seu nível socioeconômico médio-médio (considerando-se o bairro de residência e a classificação feita pelas próprias professoras). Provinham, em sua maioria, do curso de formação em magistério, exercendo a docência há 17 anos em média. As professoras de escolas públicas e particulares apresentaram alguma diferença (pouco expressiva) apenas quanto à experiência anterior de trabalho.

A entrevista semi-estruturada - posteriormente, foi feita uma entrevista semi-estruturada, seguindo um roteiro de 22 questões que abordavam vários aspectos da violência. Esta entrevista era individual e gravada em fita cassete, realizada nas dependências da escola, em data e horário marcados pela professora.

\section{Análise de dados: \\ o Sistema de Categorias para abordar a concepção de violência}

Dos dados das entrevistas e das observações, extraiu-se um Sistema de Categorias que permitiu organizar e analisar esses dados em direção aos objetivos do trabalho. O Sistema de Categorias construído, além de um instrumento de análise de dados, foi, ele próprio, considerado um importante produto da pesquisa, por contribuir para preencher uma lacuna na literatura sobre violência, cujos trabalhos apresentam, com freqüência, classificações as mais variadas, sem critérios claros e consistentes, dificultando sua organização e comparação. É importante destacar que as categorias foram surgindo dos próprios dados, e não estabelecidas a priori, com exceção das categorias Classes de Violência, em que se utilizou a categorização de Minayo (1994) e Conseqüências da Violência, em que se utilizou a categorização de Noronha et al. (1997). Como este artigo é um relato de parte de uma pesqui- 
sa mais ampla, o Sistema de Categorias aqui apresentado foi reduzido apenas às categorias referentes ao conceito de violência, extraídas do conjunto das entrevistas.

\section{As categorias referentes ao conceito de violência}

A descrição deste conceito, principal enfoque deste trabalho, agrupou sete categorias: classes, conseqüências, modalidades, formas e causas da violência; violência mais grave e violência aceitável. Para estabelecer as classes de violência, foi utilizada a categorização proposta por Minayo (1994):

- violência estrutural (opressão exercida pelos sistemas econômico, político e social e pelas instituições em geral sobre grupos, classes, nações, indivíduos);

- violência de resistência (reações à violência estrutural);

- violência de delinqüência (ações fora da lei estabelecida).

Esta classificação de Minayo foi ampliada com a introdução de uma quarta classe denominada violência de resistência deslocada, de modo a abarcar as respostas das professoras que se referiam a agressões deslocadas (reações a situações de dominação, porém dirigidas a outros alvos que não os produtores da dominação), nos moldes propostos por Bandura (1973).

As conseqüencias da violência foram categorizadas de acordo com o tipo de dano sofrido pelas vítimas da violência, na visão das professoras, como: física, social e psicológica. Como não são excludentes entre si, um único ato violento pode produzir dois ou mesmo os três tipos de dano.

As modalidades de violência foram estabelecidas levando-se em consideração os seguintes critérios: a) status que as pessoas envolvidas ocupam; b) tipo de questão-pivô da violência. Com a aplicação desses dois critérios às falas das professoras, foram identificadas doze modalidades de violência: 1) violência de marginais; 2) violência escolar; 3 ) violência familiar; 4) violência contra grupo minoritário; 5) violência política; 6) violência policial; 7) violência no trânsito; 8) violência no trabalho; 9) violência contra delinqüentes; 10) violência contra si; 11) violência contra o meio ambiente; 12 ) violência entre vizinhos. As violências escolar, familiar e contra grupo minoritário comporta- ram as submodalidades especificadas a seguir.

Violência escolar: a) entre alunos; b) de aluno para professor; c) de professor para aluno; d) de aluno para funcionário; e) de agentes externos para a escola ou seus membros; f) de aluno para a escola.

Violência familiar: a) de pais para filhos; b) de filhos para pais; c) entre membros da família; d) entre o casal.

Violência contra grupos minoritários: a) contra a criança/meninos de rua; b) contra a mulher; c) contra o negro; d) contra o idoso.

Com base na forma que a violência assume ao ser praticada, foram identificadas, nas respostas das professoras, quinze formas de violência: 1) agressão física; 2) assalto; 3) agressão verbal; 4) assassinato; 5) agressão com arma de fogo; 6) roubo; 7) abuso sexual; 8) agressão com arma branca/objeto; 9) supressão ou restrição de direitos; 10) surra/briga; 11) seqüestro; 12) coação; 13) suicídio; 14) “pega” de carro; 15) tortura.

A supressão/restrição de direitos do cidadão abarcou várias subformas de violência estrutural como, por exemplo, a falta de assistência médica ou o desemprego.

A categorização das causas aliou as características das respostas das professoras com a proposta de Bronfenbrenner (1996) para o estudo da ecologia do desenvolvimento humano, focalizando a bidirecionalidade entre pessoa e ambiente. Dessa forma, essas causas foram divididas em duas amplas categorias: contextuais e pessoais. As causas contextuais, por sua vez, foram subdivididas em distais e proximais, em função de se referirem a aspectos do contexto mais distante (sistema socioeconômico, por exemplo) ou mais próximo do indivíduo ( situação familiar, por exemplo) que pratica a violência. As causas pessoais, próprias do indivíduo, são tanto de natureza biológica como psicológica.

\section{Resultados e discussão}

As respostas das professoras às questões da entrevista foram organizadas e categorizadas de acordo com o Sistema de Categorias.

\section{As classes de violência}

A classificação da violência em estrutural, de resistência, de resistência deslocada e de de- 
linqüência é bastante geral e se apóia em bases sociológicas, nos moldes da definição de Minayo (1994), apresentada no Sistema de Categorias. São classes relacionadas de violência, com destaque para a classe estrutural como referencial para a compreensão das demais classes. Assim, tanto a própria categorização, quanto a análise das violências de resistência, de resistência deslocada e de delinqüência remetem, necessariamente, à violência estrutural. A tabela 1 mostra os dados percentuais referentes a essas quatro classes de violência. Como as classes não excluem umas às outras, uma mesma professora poderia apresentar, no seu conceito de violência, todas as quatro classes.

A violência de delinqüência faz parte do conceito de violência de todas as professoras; além disso, aproximadamente $15 \%$ citaram unicamente a violência de delinqüência. Esse dado, apesar de se referir a uma minoria das professoras, corrobora a visão de Minayo (1994) a respeito da redução da violência à delinqüência, de forma que, a despeito de toda a sua complexidade, o conceito de violência se restrinja a condutas delinqüentes e, portanto, fora da lei socialmente reconhecida. Esta redução criticada por Minayo, apesar de não estar mais presente em muitos estudos recentes sobre a violência, é freqüente em grande parte da imprensa e da população em geral. Entretanto, este reducionismo não está presente no conceito da grande maioria das professoras, já que elas citam a violência estrutural, referente à opressão, repressão, exclusão, discriminação que as estruturas organizadas e institucionalizadas (famílias e instituições sociais em geral, sistemas econômico, político, cultural) exercem sobre indivíduos, grupos, classes e nações. Apresentam, assim, uma consciência social mais ampla, desde que se mostram sensíveis à influência das estruturas sociais sobre as ações humanas e, portanto, sobre a violência que, muitas vezes, faz parte dessas ações.

As violências de resistência e de resistência deslocada aparecem no conceito de uma pequena minoria das professoras, com uma participação maior da resistência deslocada. Esta última classe foi acrescentada à classificação feita por Minayo (1994) com a finalidade de possibilitar a classificação de dados que tinham características de violência de resistência, mas que não se encaixavam nesta classe, na forma descrita por Minayo, a exemplo das falas de duas professoras, uma de escola pública e outra de escola particular:

Tem pessoas muito revoltadas, às vezes falta tudo em casa, então parte pra violência, pra roubar, pra matar.

Se ela vive num sistema, como a gente vive o nosso agora, o país, no nosso país está a fome, a saúde, a educação, tudo no lixo. Então, às vezes, a pessoa não tem aquele espírito de suportar e se torna violenta.

Os resultados revelam que a classe adicionada se mostrou adequada à classificação pretendida; ao ampliar o leque de dados classificados, mostrou-se mais abrangente e mais condizente com os padrões socioculturais vigentes na sociedade brasileira.

Em relação às classes, conclui-se que o conceito de violência das professoras inclui, na sua totalidade, a violência de delinqüência e, na sua grande maioria, a violência estrutural. As violências de resistência e de resistência deslocada aparecem no conceito de uma pequena minoria, com uma participação maior da resistência deslocada. A comparação entre as professoras de escola pública e particular mostrou que este padrão, referente às classes de violência, é o mesmo para ambos os grupos. Mostrou, também, que as porcentagens verificadas em cada classe, com exceção da violência de delinqüên-

\section{Tabela 1}

Porcentagens de professoras de escola pública $(\mathrm{N}=29)$ e de escola particular $(\mathrm{N}=18)$ que incluem, no seu conceito de violência, as violências estrutural, de resistência, de resistência deslocada e de delinqüência.

\begin{tabular}{lccc}
\hline Classes de violência & $\begin{array}{c}\text { Professoras de } \\
\text { escola pública (\%) }\end{array}$ & $\begin{array}{c}\text { Professoras de } \\
\text { escola particular (\%) }\end{array}$ & $\begin{array}{c}\text { Total } \\
\text { (\% média) }\end{array}$ \\
\hline Estrutural & 79,3 & 88,9 & 84,1 \\
Resistência & 3,4 & 5,6 & 4,5 \\
Resistência deslocada & 13,8 & 16,7 & 15,3 \\
Delinqüência & 100,0 & 100,0 & 100,0 \\
\hline
\end{tabular}


cia (100\% para os dois grupos), apesar de próximas, são sempre menores para as professoras de escola pública, com uma diferença mais acentuada nos dados relativos à violência estrutural.

\section{As conseqüências da violência}

Foram identificados, como parte da definição do conceito de violência, três tipos de conseqüência: física, social e psicológica. Na verdade, esses três termos especificam o dano produzido pela violência nas pessoas que dela são vítimas, observando-se que os tipos não se excluem mutuamente; isto quer dizer que uma mesma violência pode produzir, simultaneamente, dois ou os três tipos de dano.

A conseqüencia física foi indicada por todas as professoras entrevistadas, a social, por uma grande maioria e a psicológica, a menos citada. Tais resultados confirmam o que tem sido relatado em vários trabalhos: a violência que causa dano físico é mais facilmente identificada como violência do que a que causa dano social ou psicológico, pois o dano físico é, por sua vez, mais facilmente reconhecido como tal. O mesmo não ocorre com a conseqüência social e, mais acentuadamente, com a psicológica, que dificilmente são avaliadas como dano, até mesmo pelas vítimas da violência.

O fato de as professoras de escola particular apresentarem uma porcentagem maior de conseqüência social, e maior ainda (quase o dobro) de conseqüência psicológica, sugere a influência do ambiente de trabalho proporcionado pela escola particular. Neste, as professoras têm contato com uma clientela de um nível socioeconômico mais elevado - alunos e, especialmente, seus pais - que, por possuírem um maior nível de escolaridade e maior acesso a informações, estariam mais familiarizados com problemas sociais e psicológicos. É amplamen- te conhecido que vários alunos de escola particular, assim como seus pais, fazem uso dos serviços de profissionais de psicologia ou psiquiatria, e, inevitavelmente, acabam por trazer, para o ambiente escolar, alguma sensibilidade para os problemas psicológicos provocados pela violência.

\section{As modalidades de violência}

A categoria modalidade de violência definese pela posição das pessoas envolvidas e pela questão que foi pivô da violência, conforme já explicitado no Sistema de Categorias. Isto permitiu a identificação de doze diferentes modalidades, cuja distribuição pode ser vista na tabela 3 .

A modalidade violência de marginais faz parte do conceito de todas as professoras, o que está perfeitamente de acordo com a literatura que relata ser esta a modalidade que mais mobiliza a população de todas as camadas sociais, nela provocando fortes sentimentos de medo e insegurança. Este resultado é, ainda, coerente com o obtido em relação à classe violência de delinqüência, também presente no conceito de todas as professoras.

A violência na escola é outra modalidade que está presente no conceito de praticamente todas as professoras. Este é um resultado esperado, considerando que o ambiente escolar constitui grande parte do cotidiano dessas professoras. As subcategorias desta modalidade especificam os membros entre os quais ocorre a violência e, ainda, a direção da violência, possibilitando, dessa forma, uma caracterização mais adequada do conceito. A subcategoria mais freqüente foi a violência entre alunos, apontada por $88,2 \%$ das professoras, seguida pela violência de aluno para professor, esta última, porém, bem menos freqüente (35\%). Tais dados assemelham-se aos obtidos por Lucinda

\begin{tabular}{|c|c|c|c|}
\hline \multicolumn{4}{|c|}{$\begin{array}{l}\text { Tabela } 2 \\
\text { Porcentagem de professoras de escolas pública }(\mathrm{N}=29) \text { e particular }(\mathrm{N}=18) \text { que apresentaram, } \\
\text { no seu conceito de violência, os tipos de conseqüência: física, social e psicológica. }\end{array}$} \\
\hline Conseqüências da violência & $\begin{array}{c}\text { Professoras de } \\
\text { escola pública (\%) }\end{array}$ & $\begin{array}{c}\text { Professoras de } \\
\text { escola particular }(\%)\end{array}$ & $\begin{array}{c}\text { Total } \\
\text { (\% média) }\end{array}$ \\
\hline Física & 100,0 & 100,0 & 100,0 \\
\hline Social & 79,3 & 100,0 & 89,7 \\
\hline Psicológica & 24,1 & 44,4 & 34,3 \\
\hline
\end{tabular}


Tabela 3

Porcentagem de professoras de escola pública $(\mathrm{N}=29)$ e de escola particular $(\mathrm{N}=18)$ que incluem, no seu conceito, cada modalidade de violência.

\begin{tabular}{lccc}
\hline Modalidades de violência & $\begin{array}{c}\text { Professoras de } \\
\text { escola pública (\%) }\end{array}$ & $\begin{array}{c}\text { Professoras de } \\
\text { escola particular (\%) }\end{array}$ & $\begin{array}{c}\text { Total } \\
\text { (\% média) }\end{array}$ \\
\hline De marginais & 100,0 & 100,0 & 100,0 \\
Escolar & 96,6 & 100,0 & 98,3 \\
Familiar & 82,8 & 61,1 & 72,0 \\
Contra minorias & 44,8 & 44,4 & 44,6 \\
Política & 17,2 & 33,3 & 25,3 \\
Policial & 20,7 & 27,8 & 24,3 \\
No trânsito & 24,1 & 22,2 & 23,2 \\
No trabalho & 10,3 & 22,2 & 16,3 \\
Contra delinqüentes & 3,4 & 27,8 & 15,6 \\
Contra si & 3,4 & 16,7 & 10,1 \\
Contra meio ambiente/animais & 3,4 & 11,1 & 7,3 \\
Entre vizinhos & 3,4 & 5,6 & 4,5 \\
\hline
\end{tabular}

et al. (1999), em um trabalho sobre violência na escola, no qual os professores relatam a maior incidência de ameaças e agressões entre alunos e, depois, entre alunos e adultos, entre os quais estão incluídos os professores. Um exemplo de fala que focaliza a violência entre alunos: Sim, é demais. É violência a toda hora. É "eu vou pegar você lá fora, vou lhe furar". (...) Um quer bater no outro... Uma vez mesmo, eu fui entrar no meio e quase que tomo um murro. É assim essa violência. (...) Então, a violência na escola, dentro da escola, está sendo demais, mais do que lá fora. (...) Numa escola que fica no bairro onde eu dou aula à noite, um aluno foi baleado pelo outro. (...) Na escola pública, a violência está demais.

A violência de professor para aluno, mais citada pelas professoras de escola pública $(20,7 \%)$ que pelas de particular $(11,1 \%)$, faz parte do conceito de uma minoria das professoras. Menos freqüentes ainda foram as violências de agentes externos para a escola (8\%), de alunos para a escola (6,3\%), e de alunos para funcionários $(3,5 \%)$.

Outra modalidade bastante freqüente foi a violência familiar, que envolve membros da família e se refere a questões familiares (incluindo a questão sexual) ou ao abuso do poder conferido pela posição ocupada pelo membro da família. Neste caso, também foi necessária a especificação em sub-modalidades para melhor caracterizar o conceito: violências de pais para filhos, de filhos para pais, entre o casal e entre membros da família (citações que não espe- cificavam os membros da família). Dentre essas, a mais citada foi a violência de pais para filhos (59,5\%), exemplificada na seguinte fala sobre uma mãe e seu filho de 12 anos: Eu tenho um aluno que é acorrentado em casa. Você veja como é que vai ser o reflexo desse aluno na escola... pra ele não fazer coisas erradas, que ele já deve ter feito, a mãe acorrenta, deixa ele acorrentado. Quando ele vem pra escola, ele vem disposto a tudo. É um menino que é aviãozinho, é viciado em maconha, é viciado em crack....

Depois, mas com uma porcentagem bem menor, foi indicada a violência entre o casal $(21,1 \%)$; a seguir, com uma porcentagem menor ainda, a violência entre membros da família $(15,9 \%)$ e a violência de filhos para pais (7,3\%). Esses resultados, juntamente com a leitura cuidadosa das falas das professoras, mostram que a referência à violência familiar foi feita, na maior parte dos casos, com o objetivo de explicar, ou indicar causas, para as violências praticadas pelas pessoas em geral mas, principalmente, pelos alunos. Estes, ao serem tratados de forma violenta, ou presenciarem a violência em casa, estariam aprendendo a se comportar violentamente.

A violência contra minorias, a exemplo das duas modalidades anteriores, foi dividida em subcategorias que especificam as minorias às quais as professoras fizeram referência: violência contra criança / meninos de rua $(32,2 \%)$, contra a mulher (8\%), contra o negro $(6,3 \%) \mathrm{e}$ contra o idoso $(2,8 \%)$. Pouco menos que a metade das professoras apresentaram, no seu con- 
ceito de violência, a modalidade violência contra minorias, com uma superioridade marcante da submodalidade violência contra criança / meninos de rua, o que mostra uma preocupação maior com as crianças do que com outros grupos. Isto condiz com as características da profissão de docentes do ensino fundamental, cujo trabalho é voltado a crianças, num contato cotidiano que lhes proporciona um maior conhecimento de suas peculiaridades e, provavelmente, uma maior sensibilidade a suas necessidades. As outras três submodalidades foram indicadas em porcentagens pouco expressivas, mas inseridas em depoimentos interessantes e reveladores de uma consciência social, pelo menos parcial, da situação de discriminação social de grupos minoritários.

As violências politica, policial e no trabalho foram citadas com reprovações a injustiças, abuso de poder e desrespeito. A violência no trânsito referiu-se às condições adversas produtoras de estresse e a violência contra delinqüentes, à questão dos direitos humanos. A violência contra si abordou suicídios cometidos por exigências sociais intensas e coercitivas.

\section{As formas de violência}

Nesta categoria, foram classificados os aspectos das respostas das professoras que abrangem as especificações a respeito de como foram praticadas as modalidades de violência, já que uma mesma modalidade pode ser praticada de formas diferentes. Na tabela 4 , as quinze formas estão apresentadas em uma seqüência que parte das mais para as menos indicadas. Esta seqüência foi praticamente a mesma para os dois grupos de professoras.

A forma agressão fisica foi citada por quase todas as professoras, tanto de escola pública $(96,6 \%)$, quanto de escola particular $(94,4 \%)$. Esta forma foi utilizada para classificar as falas das professoras que usavam os rótulos: agressão física ou violência física, de forma generalizada, ou, então, que indicavam que o agressor havia feito uso de força física para praticar a violência contra a vítima. Assim, toda Forma agressão física produz Conseqüência física, mas nem todas as Conseqüências físicas são produzidas por agressão física. Elas podem ser produzidas, por exemplo, por agressão com arma de fogo ou agressão com arma branca. A presença da agressão física na fala de praticamente todas as professoras está de acordo com a literatura que relata uma maior facilidade na identificação da agressão física como violência.

$\mathrm{O}$ assalto foi também bastante presente no discurso das professoras de ambos os grupos. Foram feitos, pelas professoras, vários relatos de assaltos, ou alusões a eles, parecendo ser esta uma forma de violência que ocorre com freqüência no seu cotidiano, seja pela própria ex-

Tabela 4

Porcentagem de professoras de escola pública $(\mathrm{N}=29)$ e de escola particular $(\mathrm{N}=18)$ que incluem, no seu conceito, cada forma de violência.

\begin{tabular}{lccc}
\hline Formas de violência & $\begin{array}{c}\text { Professoras de } \\
\text { escola pública (\%) }\end{array}$ & $\begin{array}{c}\text { Professoras de } \\
\text { escola particular (\%) }\end{array}$ & $\begin{array}{c}\text { Total } \\
\text { (\% média) }\end{array}$ \\
\hline Agressão física & 96,6 & 94,4 & 95,5 \\
Assalto & 75,9 & 88,9 & 82,4 \\
Agressão verbal & 65,5 & 94,4 & 80,0 \\
Assassinato & 69,0 & 55,6 & 62,3 \\
Agressão com arma de fogo & 69,0 & 38,9 & 54,0 \\
Roubo & 44,8 & 55,6 & 50,2 \\
Abuso sexual & 41,4 & 50,0 & 45,7 \\
Agressão com arma branca / objeto & 41,4 & 44,4 & 42,9 \\
Supressão ou restrição de direitos & 37,9 & 44,4 & 41,2 \\
Briga & 31,0 & 27,8 & 29,4 \\
Coação & 17,2 & 11,1 & 14,2 \\
Seqüestro & 13,8 & 11,1 & 12,5 \\
Suicídio & 6,9 & 5,6 & 6,3 \\
"Pega" de carro & 0,0 & 5,6 & 2,8 \\
Tortura & 0,0 & 5,6 & 2,8 \\
\hline
\end{tabular}


periência ou de seus familiares e pessoas próximas, seja através de noticiários da imprensa.

A agressão verbal foi a terceira forma mais apontada pelas professoras, as quais fizeram, muitas vezes, alusões à agressão física como uma maneira de enfatizar a agressão verbal, dizendo que, às vezes, as palavras ferem mais que a violência física. É interessante notar que, dentre as formas mais citadas, a agressão verbal foi a única que guarda pouca ou nenhuma relação com a classe violência de delinqüência e com a modalidade violência de marginais. Esta presença marcante da agressão verbal no conceito das professoras está, muito provavelmente, relacionada ao seu ambiente de trabalho, no qual a agressão verbal costuma ocorrer com muito maior freqüência que a física. Já as formas assassinato, agressão com armas de fogo e roubo, assim como assalto, acima referido, estão estreitamente relacionadas com a violência delinqüencial, que ocorre em grande escala nos grandes centros urbanos, sendo que assassinato e agressão com armas de fogo são bastante freqüentes nos locais em que se situam as escolas públicas.

A forma abuso sexual foi apontada por quase metade das professoras. A maior parte dos relatos fez uso de expressões como violência sexual, estupro, abuso sexual e se referiu a abusos de crianças e adolescentes praticados por pais ou padrastos, ou a "tarados" ou "maníacos sexuais" que abusam de mulheres e, ainda, a delinqüentes que, ao praticar assaltos ou latrocínios, praticam, também, o abuso sexual.

A agressão com arma branca ou objeto, quase tão citada quanto o abuso sexual, envolveu uma grande variedade de situações como: assaltos em vias públicas, especialmente nos semáforos, brigas em escolas, casas ou ruas e em coações de vários tipos. Nestas ocorrências, as professoras citaram as armas brancas e os objetos: pedra, lápis, faca, peixeira, vidro, chave de fenda, vassoura, pedaço de pau, canivete, navalha. A maior parte das ocorrências citadas pode ser colocada na classe violência de delinqüência e na modalidade violência de marginais.

A supressão ou restrição de direitos é uma forma na qual foram classificadas as seguintes violências: desemprego, salários baixos, falta de lazer, falta de segurança, falta de escola, falta de assistência médica, falta de alimento, falta de amparo social (para as crianças), negação dos direitos dos alunos, desrespeito aos direitos do trabalhador e desrespeito aos direitos do ser humano. A supressão ou restrição de direitos, citada por $41,2 \%$ das professoras, revela uma vi- são socioestrutural da violência e se apresenta relacionada à classe violência estrutural e às modalidades violência política, violência contra minorias e violencia no trabalho.

As outras formas de violência, como mostra a tabela 4 , foram pouco indicadas pelas professoras, tanto as de escola pública como as de escola particular.

\section{A violência mais grave}

Do total das professoras, $93,8 \%$ responderam positivamente à indagação sobre a existência de violência mais grave. Destas, $93,1 \%$ foram de escola pública e $94,4 \%$ de escola particular. A análise das respostas positivas permitiu sua classificação em termos de conseqüência, modalidade e forma da violência, seguindo os mesmos critérios já estabelecidos para essas categorias. Apenas 10,1\% das professoras elegeram a violência mais grave com base na conseqüência psicológica/moral, sendo a porcentagem de professoras de escola pública $(3,4 \%)$ bem menor que a de escola particular $(16,7)$. Quando essa seleção foi feita com base na modalidade da violência, as modalidades utilizadas pelas professoras foram: violência familiar $(6,3 \%)$, contra criança/adolescente $(3,5 \%)$, racismo $(1,7 \%)$ e violência de marginais $(1,7 \%)$, também em porcentagens pequenas. $O$ principal referencial utilizado pelas professoras, na avaliação da gravidade da violência, foi a forma como ela é praticada (Tabela 5).

A forma mais citada foi, mais uma vez, a agressão física, o que constitui mais um dado que fortalece as considerações anteriores sobre a primazia e o inter-relacionamento entre a classe violência de delinqüência, a conseqüência física, a modalidade violência de marginais e a forma agressão física. Ao colocar a agressão físi$c a$ como a violência mais grave, as professoras apresentavam justificativas como: "porque fere", "machuca o corpo", "deixa marcas no corpo", "provoca dor", etc.

Depois da agressão física, as formas mais citadas foram: abuso sexual e supressão ou restrição de direitos, porém por uma porcentagem menor que a metade da referente à agressão física. O abuso sexual, na maior parte dos casos, foi especificado, pelas professoras, como estupro e considerado mais grave porque "é muito chocante" "abala psicologicamente o ser humano", "deixa marcas para o resto da vida" "principalmente se for com criança que é inocente, abala". 
Ao indicar a supressão ou restrição de direitos como forma de violência mais grave, as professoras demonstraram uma maior sensibilidade para as questões sociais, pois apontaram para problemas estruturais do tipo: "desemprego", "fome", "falta de escola", "falta de cuidado com as crianças", "abuso de poder", colocandoos como a própria violência e não como causas da violência.

Assassinato, agressão verbal, seqüestro $e$ agressão com arma de fogo ou branca foram formas pouco indicadas para avaliar a violência mais grave.

\section{A violência aceitável ou justificável}

A maioria (70,6\%) das professoras respondeu negativamente à indagação sobre violências que consideram aceitáveis ou justificáveis. Nas respostas positivas $(27,6 \%$ de escola pública e $27,8 \%$ de escola particular) foram identifi- cados quatro aspectos utilizados, pelas professoras, para respaldar sua aceitação da violência em questão: a) forma da violência; b) finalidade da violência; c) estado emocional do agressor; e d) motivação socioeconômica da violência, cujas especificações estão na tabela 6 .

Esses dados mostram que houve uma maior compreensão da violência motivada por más condições socioeconômicas do indivíduo que pratica a violência, em relação às demais violências apresentadas como aceitáveis. Apesar de ser questionável a aceitação ou a justificação de qualquer forma de violência, ao colocar justificações com base nas condições socioeconômicas do agressor, estas professoras mostraram uma visão contextualizada da violência. Exemplos dessa aceitação podem ser vistos na fala de uma professora de escola particular que disse aceitar que o indivíduo roube para comer e também considerou justificável que uma mãe abandone seu filho por absoluta falta de condi-

Tabela 5

Porcentagem de professoras de escola pública $(\mathrm{N}=29)$ e de escola particular $(\mathrm{N}=18)$ que selecionaram a violência mais grave com base em cada uma das formas de violência especificadas na tabela.

\begin{tabular}{lccc}
\hline Formas mais graves & $\begin{array}{c}\text { Professoras de } \\
\text { escola pública (\%) }\end{array}$ & $\begin{array}{c}\text { Professoras de } \\
\text { escola particular (\%) }\end{array}$ & $\begin{array}{c}\text { Total } \\
\text { (\% média) }\end{array}$ \\
\hline Agressão física & 27,6 & 27,8 & 27,7 \\
Abuso sexual & 13,8 & 11,1 & 12,5 \\
Supressão ou restrição de direitos & 13,8 & 11,1 & 12,5 \\
Assassinato & 13,8 & 5,6 & 9,7 \\
Agressão verbal & 3,4 & 11,1 & 7,3 \\
Todas as formas de violência & 6,9 & 0,0 & 3,5 \\
Seqüestro & 0,0 & 5,6 & 2,8 \\
Agressão com arma de fogo/branca & 3,4 & 0,0 & 1,7 \\
\hline
\end{tabular}

\section{Tabela 6}

Porcentagem de professoras de escola pública $(\mathrm{N}=29)$ e de escola particular $(\mathrm{N}=18)$ que consideraram aceitável algum tipo de violência, distribuídas de acordo com a justificativa apresentada para sua aceitação.

\begin{tabular}{lccc}
\hline Violências aceitáveis & $\begin{array}{c}\text { Professoras de } \\
\text { escola pública (\%) }\end{array}$ & $\begin{array}{c}\text { Professoras de } \\
\text { escola particular (\%) }\end{array}$ & $\begin{array}{c}\text { Total } \\
\text { (\% média) }\end{array}$ \\
\hline Violência verbal & 3,4 & 5,6 & 4,5 \\
Violência praticada em autodefesa & 10,3 & 0,0 & 5,2 \\
Violência praticada por agressor & 3,4 & 0,0 & 1,7 \\
com problema emocional & & 22,2 & 16,3 \\
Violência motivada por más condições & 10,3 & & \\
socioeconômicas & & & \\
\hline
\end{tabular}


ção econômica de lhe dar uma vida digna. Uma professora de escola pública achou aceitável que um desempregado, que não consegue outro emprego, assalte para viver.

Os dados a respeito da consideração da violência mais grave e da violência aceitável ou justificável foram incluídos na descrição do conceito de violência por se julgar que constituem relevantes dados complementares que cumprem a função de enriquecer e tornar mais claro o dito conceito, ao mesmo tempo em que ajudam a circunscrevê-lo.

\section{As causas da violência}

O último aspecto considerado na composição do conceito em estudo foram as causas que, segundo as professoras, estariam atuando na produção da violência. Tal consideração se fundamenta na concepção sócio-histórica sobre a importância de abarcar o contexto de produção da violência para melhor compreensão do seu conceito.

As causas foram classificadas em duas categorias amplas: causas contextuais e causas pessoais. As contextuais foram subdivididas em causas distais e causas proximais (Tabelas 7 e 8 ).

Dos nove tipos de causas distais, dois foram citados pela grande maioria das professoras: desigualdade socioeconômicalinjustiça social, $\mathrm{e}$ desempregolfome.

As falas das professoras nas entrevistas deixaram bastante clara sua visão de que a desigualdade social, causada por uma extrema concentração de renda, e também a fome e o desemprego, constituem as principais causas da violência. A mesma visão é apresentada por Pinheiro e Adorno (1993), em um trabalho sobre a violação dos direitos humanos, em que destacam, dentre os fatores causais da violência, na sociedade brasileira, a acentuada concentração de renda que tem, como conseqüência, profundas desigualdades socioeconômicas. Também presente no trabalho de Cruz Neto e Moreira (1999), esta ênfase nas desigualdades é acrescida da afirmação de que tais desigualdades são mais bem percebidas em função do forte apelo consumista promovido pela televisão, provocando frustrações que incentivam a procura ou a aceitação de formas ilegais de obtenção de ganhos fáceis. Em uma sociedade desigual, diz Pinheiro (1996), o crime é um meio para a mobilidade social.

Desemprego / fome formam um tipo de causa estreitamente relacionado à desigualdade so- cioeconômica / injustiça social e ambos estão ligados às classes violência estrutural e violência de delinqüência. Em relação à primeira, essas causas constituiriam a própria violência estrutural, enquanto em relação à segunda, elas estariam na origem da delinqüência. A ausência de linearidade fica evidente quando se trata de um fenômeno social do porte e da complexidade da violência.

A falta e/ou desorganização de escolas / falta de instrução / analfabetismo foi a terceira causa distal mais citada e está diretamente ligada à profissão das entrevistadas. Os demais tipos de causas distais foram apontados por poucas professoras.

A causa proximal mais citada pelas professoras - modelo de violência em casa / na rua / na televisão - é também considerada de extrema importância por inúmeros trabalhos sobre violência, a exemplo dos realizados por Cruz Neto e Moreira (1999), Assis e Souza (1999) e Cardia (1997). Concordando com esses trabalhos, os modelos mais freqüentemente citados pelas professoras foram os familiares, com destaque para os fornecidos pelos pais, e os apresentados pela televisão, através de filmes, desenhos ou noticiários. Tais modelos forneceriam, principalmente às crianças, subsídios para a aprendizagem dos padrões de comportamentos verbais e motores e dos significados e sentidos neles envolvidos.

As professoras colocaram a falta de estruturalorganização da família (segunda causa proximal mais freqüente) na mesma direção apontada por vários trabalhos que evidenciam a importância da família, tanto na causação, como na prevenção da violência. Por exemplo, o trabalho de Assis e Souza (1999) mostra que uma relação familiar conflituosa facilita o envolvimento do adolescente com drogas e com o mundo infracional. Cada vez mais as crianças têm experiências com conflitos e uso de drogas na família, diz Beland (1996). Com isso, diminui sua aproximação com os pais, e a televisão passa a ocupar o papel de fonte principal de valores e de entretenimento. Afirmação semelhante sobre o papel da televisão é feita por Cruz Neto e Moreira (1999), concluindo que a televisão não deixa espaço para o diálogo em família.

Dos onze tipos de causas pessoais identificados nas respostas das professoras (Tabela 9), destaca-se, como o mais citado, a dependência de drogas / álcool. O trabalho de Assis e Souza (1999), sobre fatores de risco relacionados a jo- 
Tabela 7

Porcentagem de professoras de escola pública $(\mathrm{N}=29)$ e de escola particular $(\mathrm{N}=18)$

que indicaram cada uma das causas distais da violência.

\begin{tabular}{lccc}
\hline Causas distais & $\begin{array}{c}\text { Professoras de } \\
\text { escola pública (\%) }\end{array}$ & $\begin{array}{c}\text { Professoras de } \\
\text { escola particular (\%) }\end{array}$ & $\begin{array}{c}\text { Total } \\
\text { (\% média) }\end{array}$ \\
\hline $\begin{array}{l}\text { Desigualdade socioeconômica, } \\
\text { injustiça social }\end{array}$ & 58,6 & 72,2 & 65,4 \\
$\begin{array}{l}\text { Desemprego, fome } \\
\text { Falta e/ou desorganização de escola, }\end{array}$ & 62,1 & 66,7 & 64,4 \\
falta de instrução, analfabetismo & 44,8 & 33,3 & 39,0 \\
Falta de moradia, de terra & 17,2 & 11,1 & 14,2 \\
Comportamento inadequado & 10,3 & 11,1 & 10,7 \\
dos políticos e governantes & & & \\
Competição social e/ou profissional & 3,4 & 11,1 & 7,3 \\
Não-controle da natalidade / falta & 13,8 & 0,0 & 6,9 \\
de planejamento familiar & & & \\
Abandono de crianças / crianças na rua & 10,3 & 0,0 & 5,2 \\
Impunidade social & 3,4 & 0,0 & 1,7 \\
\hline
\end{tabular}

\section{Tabela 8}

Porcentagem de professoras de escola pública $(\mathrm{N}=29)$ e de escola particular $(\mathrm{N}=18)$

que indicaram cada uma das causas proximais da violência.

\begin{tabular}{lccc}
\hline Causas proximais & $\begin{array}{c}\text { Professoras de } \\
\text { escola pública (\%) }\end{array}$ & $\begin{array}{c}\text { Professoras de } \\
\text { escola particular (\%) }\end{array}$ & $\begin{array}{c}\text { Total } \\
\text { (\% média) }\end{array}$ \\
\hline $\begin{array}{l}\text { Modelo de violência em casa / na rua / } \\
\text { na TV (ou imprensa em geral) }\end{array}$ & 62,1 & 61,1 & 61,6 \\
Falta de estrutura / organização da família & 37,9 & 38,9 & 38,4 \\
Falta de amor / afeto & 24,1 & 22,2 & 23,2 \\
Falta de dinheiro / recursos / & 17,2 & 27,8 & 22,5 \\
condições / emprego & & & 19,1 \\
Desrespeito & 10,3 & 27,8 & 15,3 \\
A própria violência & 13,8 & 16,7 & 12,8 \\
Falta de ou má orientação / educação & 3,4 & 22,2 & 4,5 \\
Falta de diálogo / compreensão & 3,4 & 5,6 & 4,5 \\
Naturalização da violência no ambiente & 3,4 & 5,6 & 2,8 \\
do agressor & & & \\
Brincadeiras com armas de brinquedo & 0,0 & 5,6 & \\
(revólver, espada, etc.) & & & \\
\hline
\end{tabular}

vens infratores, mostrou que um desses principais fatores é o consumo de drogas, além de enfatizar a rede de interligação entre uso de drogas, tipo de amigos, tipo de lazer e relação familiar conflituosa. Algumas professoras destacaram um outro aspecto, relacionando a violência à própria manutenção da dependência, ao dizer que o dependente pratica a violência para obter ganhos que lhe permitam manter seu vício.
A segunda causa pessoal mais freqüente, natureza / indole do indivíduo que pratica a violência, remete à tradicional oposição quanto à natureza inata ou social da violência, que gera uma série de divergências, como as comentadas na introdução. Briceño-León (1999) considera que a explicação que associa os traços biológicos dos indivíduos à sua agressividade é inadequada para um fenômeno social do porte da violência e propõe a perspectiva da multi- 
Tabela 9

Porcentagem de professoras de escola pública e de escola particular que apontaram cada uma das causas pessoais da violência.

\begin{tabular}{lccc}
\hline Causas pessoais & $\begin{array}{c}\text { Professoras de } \\
\text { escola pública (\%) }\end{array}$ & $\begin{array}{c}\text { Professoras de } \\
\text { escola particular (\%) }\end{array}$ & $\begin{array}{c}\text { Total } \\
\text { (\% média) }\end{array}$ \\
\hline Dependência de drogas / álcool & 34,5 & 27,8 & 31,2 \\
Natureza ou índole da pessoa & 20,7 & 16,7 & 18,7 \\
Falta de caráter / princípios, valores / dignidade & 17,2 & 16,7 & 17,1 \\
Falta de fé / religião / Deus & 20,7 & 11,1 & 15,9 \\
Egoísmo & 3,4 & 11,1 & 7,3 \\
Ganância / ambição & 3,4 & 11,1 & 7,3 \\
Falta de equilíbrio emocional & 6,9 & 5,6 & 6,3 \\
Insatisfação & 3,4 & 5,6 & 4,5 \\
Estresse & 0,0 & 5,6 & 2,8 \\
Questões passionais & 0,0 & 5,6 & 2,8 \\
Insegurança / medo & 3,4 & 0,0 & 1,7 \\
\hline
\end{tabular}

causalidade, em que as causas sociais atuam com mais intensidade. Esta é a posição de muitos outros autores cujo enfoque da violência é eminentemente social e condiz com as bases teórico-metodológicas da presente pesquisa, que afirmam o pressuposto da construção social do homem.

A maioria das professoras entrevistadas também deu uma ênfase maior às questões sociais na causalidade da violência e apenas $18,7 \%$ apresentaram a natureza / indole do indivíduo como fator causal. E ainda, nenhuma professora colocou esta causa com exclusividade; isto significa que, mesmo que em alguns pouquíssimos casos, a ênfase maior tenha recaído sobre a natureza / índole, esta causa foi sempre acompanhada da indicação de causas contextuais.

Verificou-se, ainda, que a grande maioria das professoras citou mais de um tipo de causa (apenas duas citaram um único tipo), evidenciando que as professoras, na sua quase totalidade, têm uma visão de interação entre as causas da violência e que a grande maioria identifica a interação entre causas pessoais e contextuais. Assim, a maior parte das professoras considerou todos os diferentes níveis de contexto, e a interação entre eles, apontados por Bronfenbrenner (1996), em sua abordagem ecológica do desenvolvimento humano.

Um outro dado interessante é que todas as professoras citaram causas contextuais, enquanto $76,9 \%$ das professoras citaram causas pessoais, mas sempre aliadas a causas contex- tuais, o que evidencia uma predominância da concepção da origem social da violência.

Em síntese, o conceito de violência encontrado nos dados das entrevistas caracterizouse, basicamente, pelas classes violência de delinqüência e estrutural, pelas modalidades violência de marginais, violência escolar e violência familiar e pelas formas agressão física, assalto e agressão verbal. A violência conceituada foi, ainda, contextualizada em termos de suas causas e tipos de conseqüências; estas últimas foram, preponderantemente, do tipo físico e as causas contextuais foram bem mais apontadas que as causas pessoais, mostrando uma concepção da origem socioestrutural da violência. Circunscrevendo o conceito, foi indicada, como mais grave, a violência física e como aceitável ou justificável, a violência motivada por más condições socioeconômicas.

A comparação entre a realidade das escolas públicas e particulares, nas dimensões apresentadas pelo objetivo da pesquisa, mostrou um perfil diferenciado para os dois grupos de professoras. As professoras de escola particular revelaram uma maior consciência dos problemas sociais, políticos e estruturais relacionados à violência, bem como dos danos sociais e psicológicos que a violência produz, apresentando uma visão socioestrutural da violência mais acentuada que a das professoras da rede pública.

No conceito das professoras de escola pública, estão evidentes os problemas presentes no seu cotidiano de trabalho, tanto no que se 
refere à escola propriamente dita, como no que se refere aos alunos e suas famílias e à localização da escola.

As diferenças entre os dois grupos foram relacionadas às características de seus ambientes de trabalho, bastante diferenciadas em vários aspectos, como as características da clientela atendida (níveis socioeconômico e de esco- laridade, tipo de moradia, estrutura da família, ambiente da vizinhança etc.), as características do sistema de ensino (público ou particular) e a própria situação geográfica das escolas que, apesar de se localizarem num mesmo bairro, estão, as públicas, próximas às invasões, enquanto as particulares situam-se nas partes mais nobres do bairro.

\section{Referências bibliográficas}

Assis SG \& Souza ER 1999. Criando Caim e Abel - pensando a prevenção da infração juvenil. Ciência e Saúde Coletiva 4(1):131-144.

Bandura A 1973. Agression. A social learning analysis. Englewood Clifts, Prentice Hall, Nova Jersey.

Beland KR 1996. A schoolwide approach to violence prevention, pp. 122-125. In RL Hampton, P Jenkins \& TP Gullotta (orgs.). Preventing violence in America. Sage, Califórnia.

Briceño-León R 1999. La violencia en América Latina: salud pública y cambio social, pp. 509-517. In NM Bronfman \& R Castro (orgs.). Salud, cambio social y político. Perspectivas desde América Latina. Edamex, México.

Bronfenbrenner U 1996. A ecologia do desenvolvimento humano: experimentos naturais e planejados. Artes Médicas, Porto Alegre.

Bruner J (1997). Atos de significação. Trad. Sandra Costa. Artes Médicas, Porto Alegre.

Cardia N 1997. A violência urbana e a escola. Contemporaneidade e Educação II(2):26-69.

Costa J F 1986. Violência e psicanálise. (2a ed.). Graal, Rio de Janeiro.

Cruz Neto O \& Moreira MR 1999. A concretização de políticas públicas em direção à prevenção da violência estrutural. Ciência e Saúde Coletiva 4(1):33-52.

Dadoun R (1998). A violência: ensaio acerca do "homo violens". Trad. de Pilar F. de Carvalho e Carmen de C. Ferreira. Difel, Rio de Janeiro.

Eibl-Eibsfeldt I 1970. Amor e ódio. Bertrand, Lisboa.

Emery RE \& Laumann-Billings L 1998. An overview of the nature, causes and consequences of abusive family relationships - Toward differentiating maltreatment and violence. American Psychologist 53(2): 121-135.

Figueiredo LCM 1998. Adolescência e violência: considerações sobre o caso brasileiro, pp. 53-64. In DL Levisky (org.). Adolescência - pelos caminhos da violência: a psicanálise na prática social. Casa do Psicólogo, São Paulo.

Gullo AAS 1998. Violência urbana - um problema social. Tempo Social - Revista de Sociologia da USP 10(1): 105-119.
Lorenz K 1979. A agressão - uma história natural do mal. (2a ed.). Trad. Maria Isabel Tamen. Moraes, Lisboa.

Lucinda MC, Nascimento MG \& Candau VM 1999. Escola e violência. DP\&A, Rio de Janeiro.

Martucelli D 1999. Reflexões sobre a violência na condição moderna. Tempo Social - Revista de Sociologia da USP 11(1):157-175.

Minayo MCS 1994. A violência social sob a perspectiva de saúde pública. Cadernos de Saúde Pública 10 (Suplem. 1):7-18.

Minayo MCS 1997. Violência, direitos humanos e saúde, pp. 247-260. In AM Canesqui (org). Ciências sociais e saúde. Hucitec-Abrasco, São Paulo-Rio de Janeiro.

Noronha CV, Chaves ES, Ristum M \& COSTA HG 1997. Estratégias para o controle e a prevenção da violência: uma experiência em saúde que integraliza ações, a partir da atuação de diferentes segmentos. Resumos do III Congresso Nacional da Rede UNI-IDA. Salvador.

Pinheiro PS 1996. As relações criminosas. Folha de S. Paulo, Caderno Mais, 20/9/1996.

Pinheiro PS \& Adorno S 1993. Violência contra crianças e adolescentes, violência social e estado de direito. São Paulo em Perspectiva 7(1):106-117.

Silva EG \& Tunes E 1999. Abolindo mocinhos e bandidos: o professor, o ensinar e o aprender. Editora Universidade de Brasília, Brasília.

Skinner BF 1976. Ciência e comportamento humano. (3a ed.). Trad. de João C. Todorov e Rodolpho Azzi. Edart, São Paulo.

Skinner BF 1982. Sobre o behaviorismo. Trad. de Maria da Penha Villalobos. Cultrix-Edusp, São Paulo.

Souza ER 1993. Violência velada e revelada: estudo epidemiológico da mortalidade por causas externas em Duque de Caxias, Rio de Janeiro. Cadernos de Saúde Pública 9(1):48-84.

Vygotsky LS 1984. A formação social da mente. Martins Fontes, São Paulo.

Vygotsky LS 1989. Pensamento e linguagem. (2a ed.). Martins Fontes, São Paulo.

Artigo apresentado em 15/4/2003

Aprovado em 28/5/2003

Versão final apresentada em 17/9/2003 